\title{
Performance Improvement of a Micro Impulse Water Turbine Based on Orthogonal Array
}

\author{
Lingdi Tang, Shouqi Yuan, and Yue Tang \\ Research Center of Fluid Machinery Engineering and Technology, Jiangsu University, Zhenjiang 212013, China \\ Correspondence should be addressed to Lingdi Tang; angelattld@163.com
}

Received 14 May 2017; Accepted 2 November 2017; Published 7 December 2017

Academic Editor: Jian G. Zhou

Copyright (C) 2017 Lingdi Tang et al. This is an open access article distributed under the Creative Commons Attribution License, which permits unrestricted use, distribution, and reproduction in any medium, provided the original work is properly cited.

\begin{abstract}
The study on structural design and efficiency improvement of the micro impulse water turbine with the super-low specific speed has rarely been reported in literature. In this paper, a micro impulse water turbine was optimized on the base of the orthogonal array of $\mathrm{L}_{18}\left(3^{7}\right)$ with six factors. The range analysis and variance analysis were conducted to present the significance ranking of factors and the optimal combinations of factors, aiming to improve the water turbine efficiency taken as the experimental indicator in the orthogonal experiment. And then the optimal parameter combination for the water turbine was calculated by orthogonal experiment. Moreover, the internal flow field and hydraulic performance were simulated numerically to investigate the principle of performance improvement by comparing the optimized water turbine with the original. Also, the numerical method was verified by experimental result from performance tests of the original water turbine. As a result, the runner torque of the optimized water turbine was $13 \%$ higher than that of the original and the water turbine efficiency was improved by 5.8 percentage points at the rated operating condition.
\end{abstract}

\section{Introduction}

Water resource is only the clean and renewable energy and applicable for the large-scale development by far. Hydraulic turbine has been used to convert hydraulic energy into mechanical energy or electric energy for centuries in several fields. In industry, the water turbine is applied to recycle the energy from industrial water [1-4] or drive the cooling tower fan [5-11]. In agriculture, the water turbine in irrigation machinery is used to rotate the nozzle and move the sprinkler trolley [12-14]. The water turbine is not only used in large hydropower station as large as a unit capacity of $700 \mathrm{MW}$ but is also applied to power a sensor as small as a micro pipeline turbine [15-17]. The orthogonal experimental design is a method based on orthogonal array to obtain an optimal scheme with multiple factors and levels in a certain range. The orthogonal array can maximize the test coverage while minimizing the number of test cases to consider and can be used in various fields. An orthogonal experimental design considering the interactions was used to obtain an optimized wind rotor to improve energy utilization of vertical axis wind turbine. Three factors including radius of curvature, installation angle, and central angle of small arc were selected in this orthogonal experimental design [18]. The effect degree of main geometry factors of splitter blade on the performance of pump as turbine was obtained (in order, the outlet deflection angle, the outlet diameter, the number of blades, and the blades circumferential biasing degrees) based on the $\mathrm{L}_{9}\left(3^{4}\right)$ orthogonal design method [19]. The structure of turbine blade was optimized by a seven-factor orthogonal array with the Kriging model to maximize the fatigue life of turbine blade [20]. The orthogonal experiment design method was applied to evaluate the performance of ASHP (air source heat pump). The optimized ASHP with optimum parameter combination was proposed and the most significant parameter was identified [21]. The control parameter of the industrial controller was tuned through an orthogonal test considering the interactions to match the characteristics of the controlled system [22]. Moreover, an optimal scheduling method of urban pumping stations was proposed based on orthogonal array to cut down the energy cost. The total electric power consumption in a study case 
with the optimized scheduling method reduced more than $1 / 4$ compared with the traditional one [23].

Water turbine mainly has two types, impulse turbine and reaction turbine; the former works in nonpressure system while the latter works in pressure system. Moreover, the pump reversal is also used as the turbine. The water turbine from large scale to small scale has drawn enough attention. However, researches on structural design and efficiency improvement of the micro water turbine with the power less than $1 \mathrm{~kW}$, especially for the super-low specific speed one (less than $20 \mathrm{~m} \cdot \mathrm{kW}$ ), are still inadequate. In this paper, the orthogonal array was used to improve the performance of the original water turbine by combining with numerical simulations. The result of orthogonal design was analyzed by the statistical method to rank the significance of factors, and the optimized water turbine with optimal combination of factors was proposed.

\section{Materials and Methods}

2.1. Geometry and Meshing for the Water Turbine. The entity and three-dimensional model of the original water turbine are shown in Figure 1. The specific speed under the rated working condition is 14.55 . The rated rotational speed $\left(n_{e}\right)$ of water turbine is $700 \mathrm{rpm}$, the rated flow $\left(Q_{e}\right)$ is $17.5 \mathrm{~m}^{3} / \mathrm{h}$, and the operation condition ranges from $15 \mathrm{~m}^{3} / \mathrm{h}$ to $21 \mathrm{~m}^{3} / \mathrm{h}$.

The polyhedral mesh was used in the entire computational domain of water turbine as shown in Figure 2.
The mesh was generated with a combination of surface remesh, polyhedral mesher, and prism layer mesher. The grid independence was conducted, and the result is presented in Table 1 . It shows that the head and efficiency basically remain about the same (the variation magnitude less than $2 \%$ ) when the grid number is greater than $10^{6}$. Thus, the mesh scheme 3 was used in this work.

2.2. Governing Equations. The three-dimensional governing equation $[24,25]$ of mass and momentum conservation for steady, turbulent, incompressible flow can be written in Cartesian tensor form as

$$
\begin{aligned}
\frac{\partial}{\partial x_{i}}\left(\rho u_{i}\right)= & 0, \\
\frac{\partial}{\partial x_{j}}\left(\rho u_{i} u_{j}\right)= & -\frac{\partial p}{\partial x_{i}}+\frac{\partial}{\partial x_{j}}\left[\mu\left(\frac{\partial u_{i}}{\partial x_{j}}+\frac{\partial u_{j}}{\partial x_{i}}\right)\right] \\
& +\frac{\partial}{\partial x_{j}}\left(-\rho \overline{u_{i}^{\prime} u_{j}^{\prime}}\right)
\end{aligned}
$$

where $\rho$ is liquid density and $\mu$ is dynamic viscosity.

The SST $k$ - $\omega$ turbulence model was used for turbulence closure. The turbulence kinetic energy $k$ and the specific dissipation rate $\omega$ are obtained from the following transport equations:

$$
\begin{aligned}
& \frac{\partial}{\partial t}(\rho k)+\frac{\partial}{\partial x_{i}}\left(\rho k u_{i}\right)=\frac{\partial}{\partial x_{j}}\left[\left(\mu+\frac{\mu_{t}}{\sigma_{k}}\right) \frac{\partial k}{\partial x_{j}}\right]+\left[\min \left(-\rho \overline{u_{i}^{\prime} u_{j}^{\prime}} \frac{\partial u_{j}}{\partial x_{i}}, 10 \rho \beta^{*} k \omega\right)\right]-\rho \beta^{*} k \omega_{k}, \\
& \frac{\partial}{\partial t}(\rho \omega)+\frac{\partial}{\partial x_{j}}\left(\rho \omega u_{j}\right)=\frac{\partial}{\partial x_{j}}\left[\left(\mu+\frac{\mu_{t}}{\sigma_{\omega}}\right) \frac{\partial \omega}{\partial x_{j}}\right]+\frac{\omega}{k}\left(-\rho \overline{u_{i}^{\prime} u_{j}^{\prime}} \frac{\partial u_{j}}{\partial x_{i}}\right)-\rho \beta_{i} \omega^{2}+2\left(1-F_{1}\right) \rho \frac{1}{\omega \sigma_{\omega, 2}} \frac{\partial k}{\partial x_{j}} \frac{\partial \omega}{\partial x_{j}} \\
& \mu_{t}=\frac{\rho k}{\omega} \frac{1}{\max \left(1 / \alpha^{*}, S F_{2} / \alpha_{1} \omega\right)} \\
& \beta_{i}=F_{1} \beta_{i, 1}+\left(1-F_{1}\right) \beta_{i, 2} \\
& F_{1}=\tanh \left\{\left\{\min \left[\max \left(\frac{\sqrt{k}}{0.09 \omega y}, \frac{500 \mu}{\rho y^{2} \omega}\right), \frac{4 \rho k}{\sigma_{\omega, 2} \max \left(2 \rho\left(1 / \sigma_{\omega, 2}\right)(1 / \omega)\left(\partial k / \partial x_{j}\right)\left(\partial \omega / \partial x_{j}\right), 10^{-10}\right) y^{2}}\right]\right\}\right. \\
& F_{2}=\tanh \left\{\left[\max \left(2 \frac{\sqrt{k}}{0.09 \omega y}, \frac{500 \mu}{\rho y^{2} \omega}\right)\right]^{2}\right\}
\end{aligned}
$$

where $\mu_{t}$ is turbulent viscosity, $S$ is strain rate, and the coefficients are as follows: $\alpha^{*}=1, \alpha_{1}=0.31, \beta^{*}=0.09$, $\sigma_{k, 1}=1.176, \sigma_{k, 2}=1.0, \sigma_{\omega, 1}=2.0, \sigma_{\omega, 2}=1.168, \beta_{i, 1}=0.075$, $\beta_{i, 2}=0.0828$.

2.3. Calculation Method and Boundary Conditions. Threedimensional steady flow field of water turbine was solved by the commercial software Star-ccm+. The computational domain includes inlet section (stationary domain), outlet section (stationary domain), and runner section (rotating domain). Data between neighboring domains was transmitted through interface. The reference coordinate system for rotating domain is the rotating frame rotated about the runner central axis and for stationary domain is the lab reference frame. And the other setups for numerical calculation are shown in Table 2. 

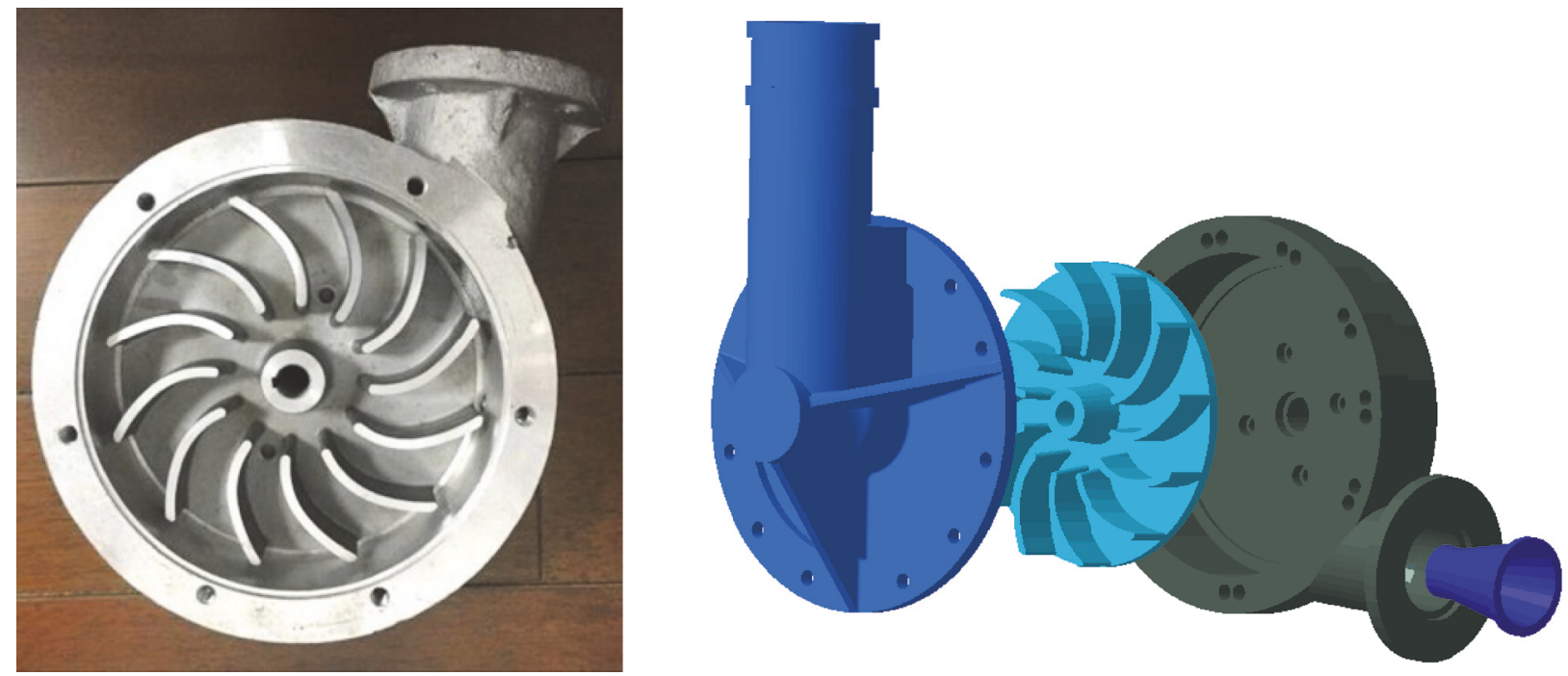

FIGURE 1: The original water turbine.
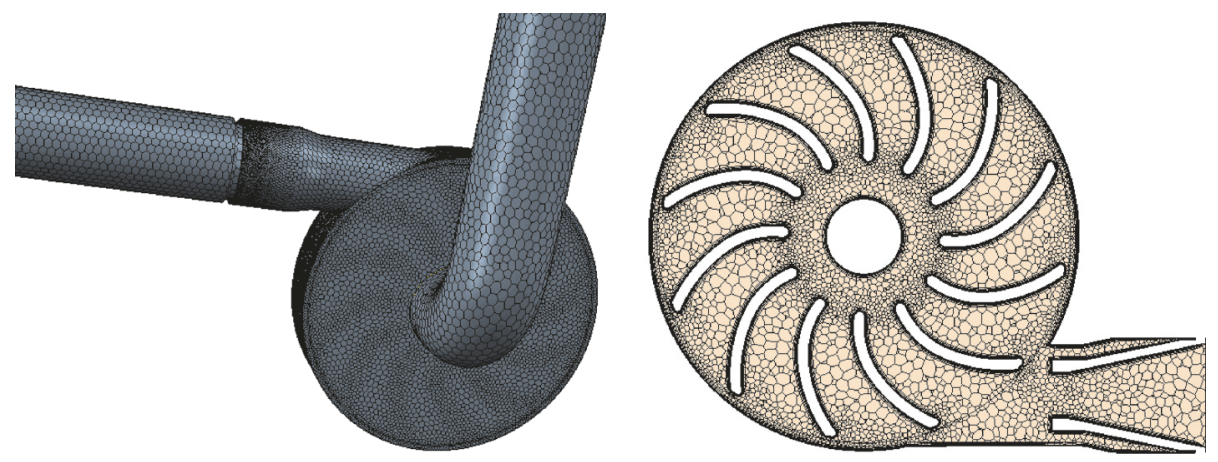

(a)

(b)

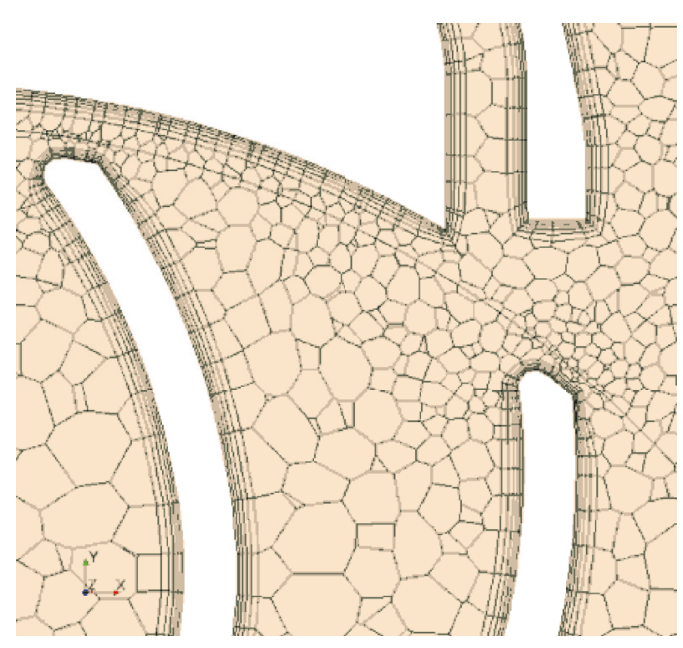

(c)

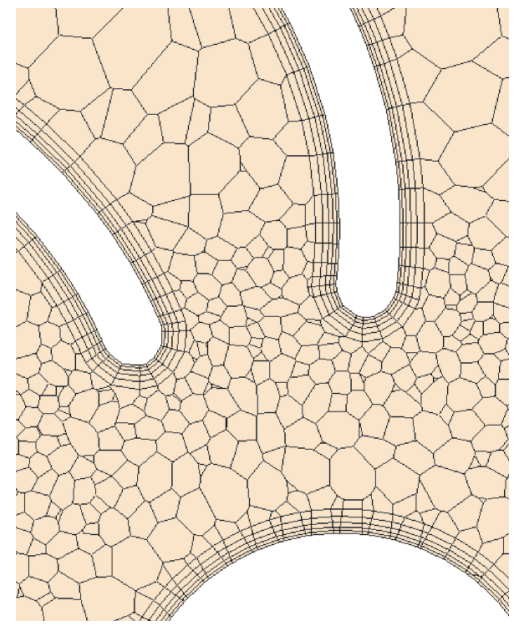

(d)

Figure 2: Water turbine meshes. (a) Three-dimensional meshes. (b) Radial cross-section meshes. (c) Local meshes of blade tip. (d) Local meshes of blade outlet. 
TABLE 1: Grid independence analysis.

\begin{tabular}{lccccc}
\hline Mesh scheme & 1 & 2 & 3 & 4 & 5 \\
\hline Grid number & 378861 & 569762 & 1141389 & 2386757 & 4696273 \\
Grid size/mm & 6 & 4 & 2 & 34.32 & 34.02 \\
$\eta / \%$ & 36.03 & 35.01 & 11.97 & 11.95 & 33.87 \\
$H / \mathrm{m}$ & 12.56 & 12.32 & 11.96 \\
\hline
\end{tabular}

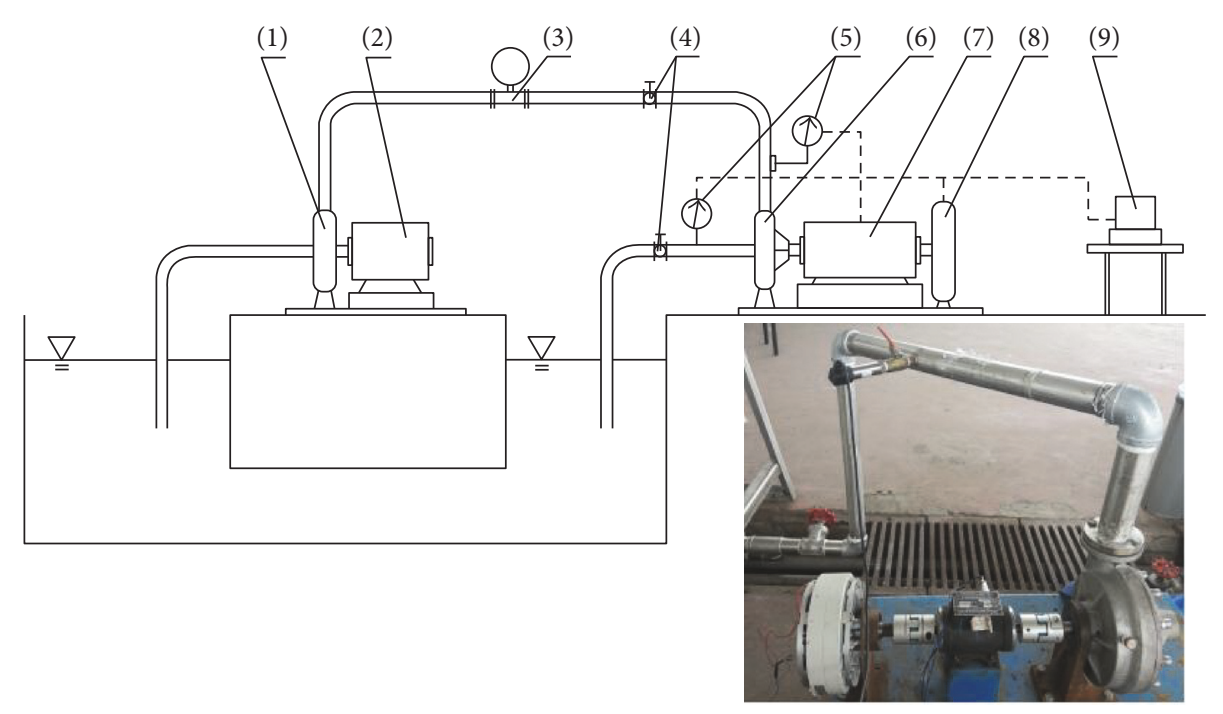

FIGURE 3: Schematic diagram of experimental apparatus. (1) Water supply pump; (2) motor; (3) electromagnetic flowmeter; (4) regulating valve; (5) pressure gauge; (6) tested water turbine; (7) torque-revolution speed transducer; (8) magnetic powder brake; (9) measuring system.

TABLE 2: The primary setup for numerical calculation.

\begin{tabular}{ll}
\hline Space & Three-dimensional \\
Time & Steady \\
Material & Liquid \\
Flow & Segregated \\
Equation of state & Constant density \\
Viscous regime & Turbulent \\
Reynolds-averaged turbulence & K-omega turbulence \\
Transition & Turbulence suppression \\
K-omega wall treatment & All $y+$ wall treatment \\
Gradient metrics & Gradients \\
\hline
\end{tabular}

At the inlet boundary, the uniform inlet velocity $\left(v_{\text {in }}\right)$ is prescribed with the turbulence intensity $(I)$.

$$
v_{\text {in }}=\frac{4 Q_{\text {in }}}{\pi d_{\text {in }}^{2}},
$$

where $Q_{\text {in }}$ is inlet flow rate and $d_{\text {in }}$ is inlet pipe diameter.

$$
I=0.16 \operatorname{Re}^{-1 / 8}=0.16\left(\frac{\rho v d}{\mu}\right)^{-1 / 8},
$$

where Re is Reynolds number, $v$ equals $v_{\text {in }}$, and $d$ equals $d_{\text {in }}$.

At the outlet boundary, the pressure outlet with the relative static pressure of $0.3 \mathrm{MPa}$ according to the actual working status and the turbulence intensity calculated by (4) are fixed. At the wall boundary, a no-slip condition is imposed with the roughness of $0.025 \mathrm{~mm}$.

\section{Experimental Validation}

The performance test of water turbine was conducted in an open test rig as shown in Figure 3. The test apparatus includes a water turbine, a water supply pump, a regulating valve, a magnetic powder brake, a torque-revolution speed transducer, an electromagnetic flowmeter, torque-rotational speed measurer, and two pressure gauges.

The water supply pump absorbs water from the reservoir, then, the water is pressured by pump and flows to the water turbine as the pressured water. The water flow was regulated by a valve, and its magnitude is measured by a flowmeter installed between pump outlet and water turbine inlet. The length of upstream pipeline of the flowmeter is about ten times the pipe diameter, and the length of downstream pipeline of the flowmeter is about five times the pipe diameter. Pressure measurements were conducted by pressure sensors installed at both the inlet and outlet of the water turbine, and measuring positions were both placed at the distance with double pipe diameter. The shaft of water turbine, torque sensor, and magnetic powder brake were connected by flexible coupling with the concentricity less than $20 \mu \mathrm{m}$.

Comparisons between numerical simulation results and test results are shown in Figure 4. The maximum relative error 

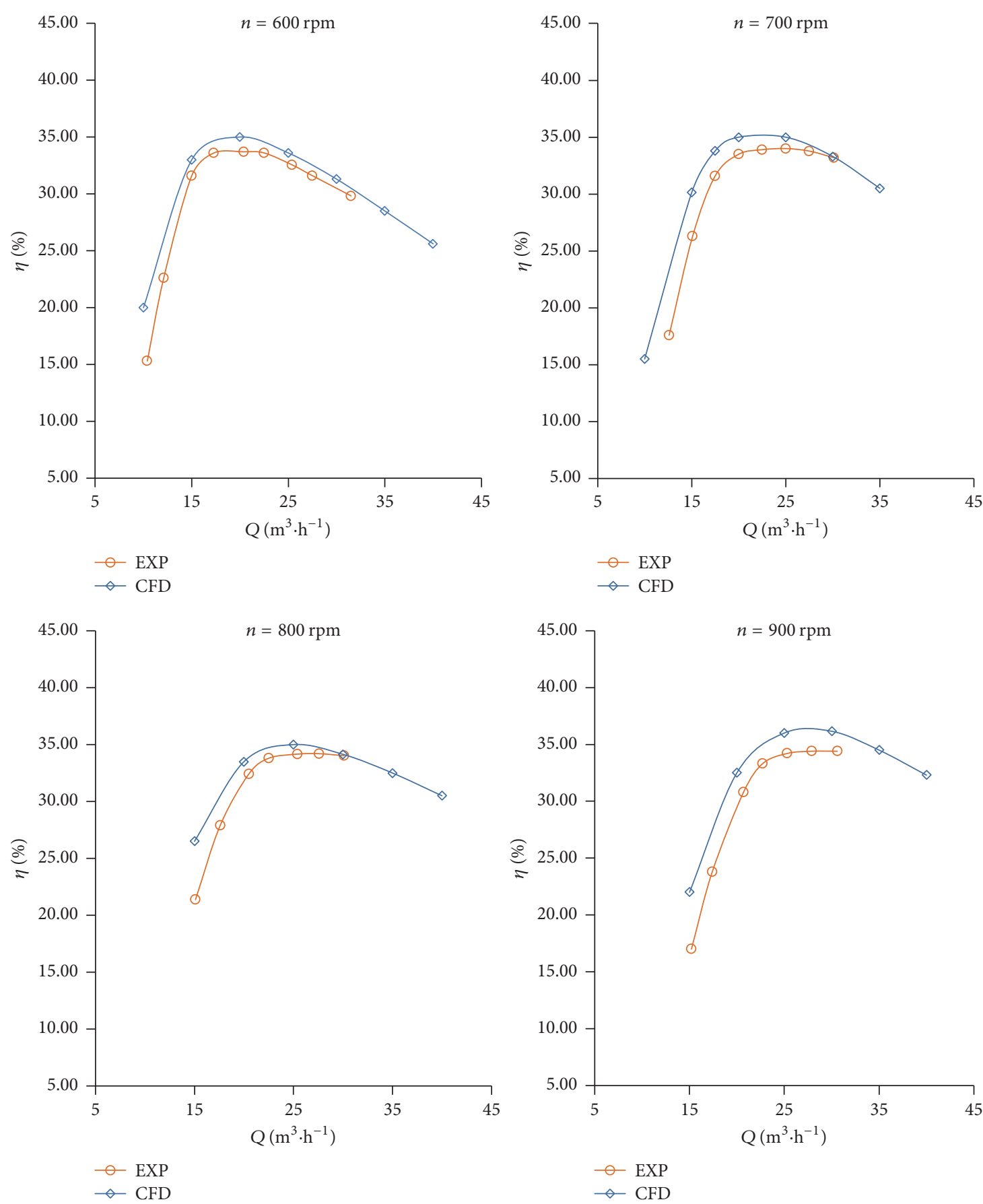

FIGURE 4: Comparisons between numerical simulation results and test results.

is less than $5 \%$, which indicates a good agreement between measured and calculated results. The efficiency curves of the original water turbine under different rotating speed conditions show that the performance in low rotation speed is lower than in high rotation speed, with the increase of rotation speed, the maximum efficiency running point moves towards the direction of high flow, and the high efficiency area goes wider.

\section{Results and Discussions}

4.1. Orthogonal Experimental Design. The influential factors of the water turbine runner were selected from all the geometric parameters, and each factor contained three levels, as shown in Table 3.

The orthogonal experiment is supposed to present a new type water turbine runner with the high hydraulic 
TABLE 3: Factors and levels of orthogonal experiment.

\begin{tabular}{|c|c|c|c|c|c|c|}
\hline \multirow[b]{2}{*}{ Level } & \multicolumn{6}{|c|}{ Factor } \\
\hline & $\begin{array}{c}\text { Number of blades } \\
Z\end{array}$ & $\begin{array}{l}\text { Blade tip clearance } \\
\qquad \delta\end{array}$ & $\begin{array}{l}\text { Width of blade } \\
\qquad b\end{array}$ & $\begin{array}{l}\text { Inlet blade angle } \\
\beta_{p}\end{array}$ & $\begin{array}{c}\text { Blade outlet } \\
\text { diameter } \\
D_{2}\end{array}$ & $\begin{array}{c}\text { Inclination angle of } \\
\text { blade outlet } \\
\gamma_{2}\end{array}$ \\
\hline 1 & 10 & 7 & 26 & 155 & 65 & 50 \\
\hline 2 & 12 & 5 & 28 & 145 & 72 & 60 \\
\hline 3 & 14 & 2 & 31 & 135 & 80 & 70 \\
\hline
\end{tabular}

TABLE 4: Orthogonal experiment schemes.

\begin{tabular}{|c|c|c|c|c|c|c|c|}
\hline Number & $\mathrm{A} / Z$ & $\mathrm{~B} / \delta$ & $\mathrm{C} / b$ & $\mathrm{D} / \alpha_{1}$ & $\mathrm{E} / D_{2}$ & $\mathrm{~F}$ & $\mathrm{G} / \gamma_{2}$ \\
\hline (1) & Al (10) & $\mathrm{B} 1(7)$ & $\mathrm{Cl}(26)$ & D1 (155) & E1 (65) & $\mathrm{F} 1$ & G1 (50) \\
\hline (2) & $\mathrm{A} 1$ & B2 (5) & C2 (28) & D2 (145) & E2 (72) & $\mathrm{F} 2$ & G2 (60) \\
\hline (3) & $\mathrm{A} 1$ & B3 (2) & C3 (31) & D3 (135) & E3 (80) & F3 & G3 (70) \\
\hline (4) & A2 (12) & $\mathrm{B} 1$ & $\mathrm{C} 1$ & D2 & E2 & F3 & G3 \\
\hline (5) & $\mathrm{A} 2$ & B2 & $\mathrm{C} 2$ & D3 & E3 & $\mathrm{F} 1$ & G1 \\
\hline (6) & $\mathrm{A} 2$ & B3 & C3 & D1 & E1 & F2 & G2 \\
\hline (7) & A3 (14) & B1 & $\mathrm{C} 2$ & D1 & E3 & $\mathrm{F} 2$ & G3 \\
\hline (8) & A3 & B2 & C3 & D2 & E1 & F3 & G1 \\
\hline (9) & A3 & B3 & $\mathrm{C} 1$ & D3 & E2 & $\mathrm{F} 1$ & G2 \\
\hline (10) & $\mathrm{A} 1$ & B1 & $\mathrm{C} 3$ & D3 & E2 & $\mathrm{F} 2$ & G1 \\
\hline (11) & $\mathrm{A} 1$ & B2 & $\mathrm{C} 1$ & D1 & E3 & F3 & G2 \\
\hline (12) & $\mathrm{A} 1$ & B3 & $\mathrm{C} 2$ & D2 & E1 & $\mathrm{F} 1$ & G3 \\
\hline (13) & $\mathrm{A} 2$ & B1 & $\mathrm{C} 2$ & D3 & E1 & F3 & G2 \\
\hline (14) & $\mathrm{A} 2$ & B2 & $\mathrm{C} 3$ & D1 & E2 & $\mathrm{F} 1$ & G3 \\
\hline (15) & $\mathrm{A} 2$ & B3 & $\mathrm{C} 1$ & D2 & E3 & $\mathrm{F} 2$ & G1 \\
\hline (16) & A3 & B1 & C3 & D2 & E3 & F1 & $\mathrm{G} 2$ \\
\hline (17) & A3 & B2 & $\mathrm{C} 1$ & D3 & E1 & $\mathrm{F} 2$ & G3 \\
\hline (18) & A3 & B3 & $\mathrm{C} 2$ & D1 & E2 & F3 & G1 \\
\hline
\end{tabular}

Note. A is number of blades, B is blade tip clearance, $\mathrm{C}$ is width of blade, $\mathrm{D}$ is inlet blade angle, $\mathrm{E}$ is blade outlet diameter, $\mathrm{F}$ is vacancy, and $\mathrm{G}$ is inclination angle of blade outlet.

performance. The efficiency $(\eta)$ was regarded as the indicator to evaluate the hydraulic performance of water turbine.

$$
\eta=\frac{P_{s}}{P_{w}} \times 100 \%,
$$

where $P_{s}$ is the shaft power (output power) (W) and $P_{w}$ is the water power (input power) (W).

$$
\begin{aligned}
P_{w} & =\rho g Q H, \\
P_{s} & =\frac{2 \pi n M}{60} \\
H & =\frac{\Delta p}{\rho g}
\end{aligned}
$$

where $\rho$ is the fluid density $\left(\mathrm{kg} / \mathrm{m}^{3}\right), g$ is the gravitational acceleration $(9.8 \mathrm{~N} / \mathrm{kg}), n$ is the rotational speed (rpm), $M$ is the runner torque $(\mathrm{N} \cdot \mathrm{m})$, and $\Delta p$ is the pressure drop from the inlet of water turbine to the outlet of water turbine $(\mathrm{Pa})$.

The orthogonal array without considering interactions requires six columns for six-factor analysis (three levels for each factor) and at least one vacant column for error analysis. The vacant column with no contributing factor can well reflect the error induced by random chance, and it takes effect in the subsequent statistical data analysis. The vacant column (also called the error column) guarantees the reliability of the experimental results. Thus, the orthogonal array of $\mathrm{L}_{18}\left(3^{7}\right)$ was determined in this study. The whole experimental arrangement including 18 times is shown in Table 4.

The performance of the water turbine is expected to keep the high efficiency in common used conditions. Thus, all the water turbine efficiencies in the low-flow condition $\left(0.8 Q_{e}\right)$, the rated flow condition $\left(1.0 Q_{e}\right)$, and the high-flow condition $\left(1.2 Q_{e}\right)$ were observed, as shown in Table 5 .

4.2. Direct Analysis of the Orthogonal Experiment Results. The direct analysis for the experimental results is to determine the important order of all factors by means of the range analysis. The range analysis in this study reveals the influence extent for the efficiency of water turbine by comparisons among mean values and range values in different factors. Range analyses of orthogonal experiment results in three operating conditions are shown in Table $6 . K_{m}$ is the sum of 
TABLE 5: Orthogonal experiment results at the rated rotational speed $\left(n_{e}=700 \mathrm{r} / \mathrm{min}\right)$.

\begin{tabular}{llll}
\hline Number & $0.8 Q_{e}$ & $1.0 Q_{e}$ & $1.2 Q_{e}$ \\
\hline$(1)$ & 34.52 & 34.92 & 35.45 \\
$(2)$ & 30.89 & 31.46 & 31.13 \\
$(3)$ & 29.63 & 30.39 & 30.22 \\
$(4)$ & 35.80 & 36.32 & 37.26 \\
$(5)$ & 25.30 & 26.91 & 27.77 \\
$(6)$ & 37.87 & 39.10 & 38.98 \\
$(7)$ & 31.69 & 32.74 & 32.94 \\
$(8)$ & 34.58 & 35.46 & 35.36 \\
$(9)$ & 34.61 & 35.30 & 35.22 \\
$(10)$ & 29.96 & 30.46 & 30.46 \\
$(11)$ & 28.23 & 29.48 & 29.47 \\
$(12)$ & 35.68 & 35.85 & 35.19 \\
$(13)$ & 35.56 & 36.49 & 36.56 \\
$(14)$ & 37.81 & 39.27 & 39.68 \\
$(15)$ & 28.13 & 30.36 & 31.32 \\
$(16)$ & 32.90 & 33.55 & 33.38 \\
$(17)$ & 34.64 & 35.42 & 36.18 \\
$(18)$ & 31.39 & 31.77 & 31.58 \\
\hline
\end{tabular}

efficiencies at the $m$ th level for a certain factor in one column, and $k_{m}$ is the mean value of $K_{m} . R$ is the range for certain factor in one column and can be calculated by (7) [26]. The value of $k_{m}$ indicates that the $m$ th level for a certain factor is either a superior level or an inferior level, and the value of $R$ indicates the changing amplitude of the water turbine efficiency with the variation of levels for a certain factor. The higher value of $R$ shows the greater effect on water turbine efficiency. Therefore, the descending order of the $R$ value is the important order of factors, as shown in Table 7.

$$
R=\max k_{m}-\min k_{m}
$$

The range of vacant column means the limit of error; it is used to estimate whether a factor has an effect on the water turbine efficiency. The factor is an influential one if the range of this factor is larger than the range of vacant column, while the factor is an effect-free one if the range of this factor is less than the range of vacant column and the range of this factor is considered to be caused by experimental error.

As shown in Table 7, factor E (blade outlet diameter) is the most important factor while factor B (blade tip clearance) is the least important factor for the observed operating conditions $\left(0.8 Q_{e}, 1.0 Q_{e}\right.$, and $\left.1.2 Q_{e}\right)$. Factors $G$, $C$, and $D$ always have the significance relation that $G>C>D$. Factor A presents different significance in different operating conditions. It is a less important factor in low-flow operating condition and a secondary important factor in both rated and high-flow operating conditions.

The relations between efficiencies and factors are shown in Figure 5. It clearly shows the effects of factor on the efficiency of water turbine and the variation trend of the efficiency with levels of factor.

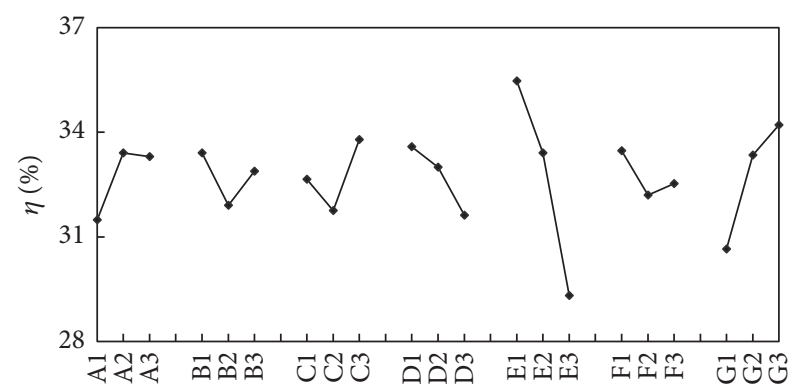

(a)

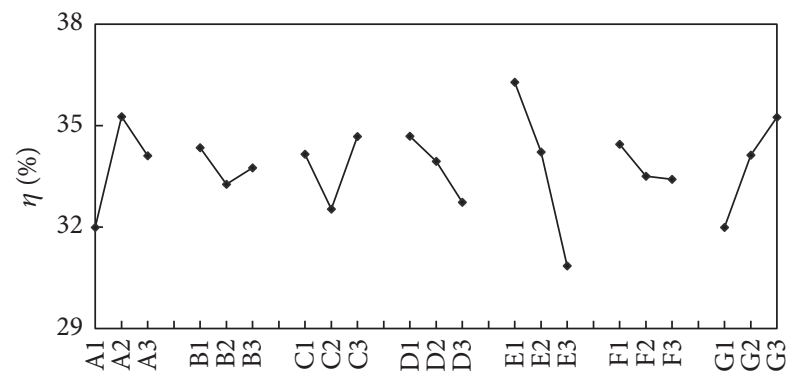

(b)

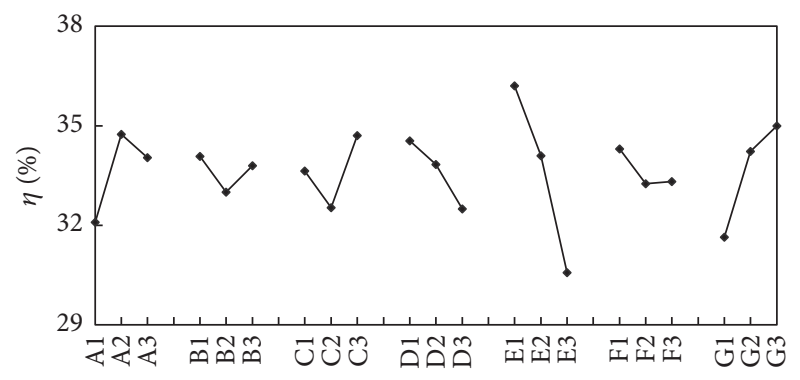

(c)

FIGURE 5: Relations between efficiencies and factors. (a) $0.8 Q_{e}$; (b) $1.0 Q_{e} ;(\mathrm{c}) 1.2 Q_{e}$.

The factors show the nearly same change rules in lowflow operating condition $\left(0.8 Q_{e}\right)$, rated operating condition $\left(1.0 Q_{e}\right)$, and high-flow operating condition $\left(1.2 Q_{e}\right)$.

For factor A, the efficiency of level A2 is the highest, and the efficiency of level A3 is slightly less than that of level A2, while the efficiency of level $\mathrm{A} 1$ is obviously lower than that of level A2 and level A3. For factor B, the efficiency of level $\mathrm{B} 1$ is the highest, followed by that of level B3 and level B2, but the differences among them are quite modest. For factor C, the efficiency of level C3 is the highest, and the efficiency of level $\mathrm{C} 1$ is little higher than that of level A2. For factor $\mathrm{D}$, the efficiency of level $\mathrm{D} 1$ is the highest, and efficiencies of levels D1, D2, and D3 decrease in sequence. For factor E, the efficiency of level E1 is the highest, and efficiencies of levels $\mathrm{E} 1, \mathrm{E} 2$, and E3 descend in turn with the largest change range. Factor $\mathrm{F}$ is vacant. For factor $\mathrm{G}$, the calculated efficiency of level G3 is the highest, and efficiencies of levels G1, G2, and G3 increase in sequence, with the second largest change range. The level with the highest efficiency for each factor (A2, B1, C3, D1, E1, and G3) can be combined to structure a new water turbine with the better performance. 
TABLE 6: Range analyses of orthogonal experiment results.

\begin{tabular}{|c|c|c|c|c|c|c|c|c|}
\hline \multirow{7}{*}{$0.8 Q e$} & $K_{1}$ & 188.90 & 200.42 & 195.93 & 201.51 & 212.84 & 200.82 & 183.88 \\
\hline & $K_{2}$ & 200.45 & 191.44 & 190.50 & 197.97 & 200.46 & 193.17 & 200.06 \\
\hline & $K_{3}$ & 199.82 & 197.31 & 202.74 & 189.69 & 175.87 & 195.18 & 205.23 \\
\hline & $k_{1}$ & 31.48 & 33.40 & 32.65 & 33.58 & 35.47 & 33.47 & 30.65 \\
\hline & $k_{2}$ & 33.41 & 31.91 & 31.75 & 32.99 & 33.41 & 32.19 & 33.34 \\
\hline & $k_{3}$ & 33.30 & 32.88 & 33.79 & 31.62 & 29.31 & 32.53 & 34.21 \\
\hline & $R$ & 1.93 & 1.50 & 2.04 & 1.97 & 6.16 & 1.28 & 3.56 \\
\hline \multirow{7}{*}{$1.0 Q_{e}$} & $K_{1}$ & 192.56 & 204.48 & 201.80 & 207.28 & 217.23 & 205.79 & 189.87 \\
\hline & $K_{2}$ & 208.46 & 198.00 & 195.22 & 203.00 & 204.57 & 199.54 & 205.38 \\
\hline & $K_{3}$ & 204.23 & 202.76 & 208.22 & 194.97 & 183.44 & 199.91 & 210.00 \\
\hline & $k_{1}$ & 32.09 & 34.08 & 33.63 & 34.55 & 36.21 & 34.30 & 31.65 \\
\hline & $k_{2}$ & 34.74 & 33.00 & 32.54 & 33.83 & 34.09 & 33.26 & 34.23 \\
\hline & $k_{3}$ & 34.04 & 33.79 & 34.70 & 32.49 & 30.57 & 33.32 & 35.00 \\
\hline & $R$ & 2.65 & 1.08 & 2.17 & 2.05 & 5.63 & 1.04 & 3.35 \\
\hline \multirow{7}{*}{$1.2 Q_{e}$} & $K_{1}$ & 191.91 & 206.05 & 204.89 & 208.09 & 217.71 & 206.69 & 191.94 \\
\hline & $K_{2}$ & 211.58 & 199.58 & 195.16 & 203.64 & 205.33 & 201.00 & 204.73 \\
\hline & $K_{3}$ & 204.65 & 202.50 & 208.08 & 196.40 & 185.10 & 200.45 & 211.46 \\
\hline & $k_{1}$ & 31.98 & 34.34 & 34.15 & 34.68 & 36.28 & 34.45 & 31.99 \\
\hline & $k_{2}$ & 35.26 & 33.26 & 32.53 & 33.94 & 34.22 & 33.50 & 34.12 \\
\hline & $k_{3}$ & 34.11 & 33.75 & 34.68 & 32.73 & 30.85 & 33.41 & 35.24 \\
\hline & $R$ & 3.28 & 1.08 & 2.15 & 1.95 & 5.43 & 1.04 & 3.25 \\
\hline
\end{tabular}

TABLE 7: Important order of factors.

\begin{tabular}{lllcccc}
\hline Operating condition & \multicolumn{6}{c}{ Major $\rightarrow$ minor } \\
\hline $0.8 Q_{e}$ & E & G & C & D & A & B \\
$1.0 Q_{e}$ & E & A & G & C & D & B \\
$1.2 Q_{e}$ & E & A & G & C & D & B \\
\hline
\end{tabular}

In comparison to the change range of factor $\mathrm{F}$ (vacancy), factor B has basically the same change range, all the factors A, $\mathrm{C}$, and $\mathrm{D}$ have slightly larger change ranges, and both factors $\mathrm{E}$ and $G$ have significantly larger change ranges. Therefore, the effect of factor B on water turbine efficiency can be neglected, while the effect of other factors on the efficiency should be further investigated.

4.3. Variance Analysis of the Orthogonal Experiment Results. The range analysis is simple and convenient, but it does not consider the influence of experimental error on experimental indicator and not calculate the magnitude of experimental error. Thus, it is unable to distinguish the change of experimental indicator resulting from factors various and experimental error. Moreover, the range analysis is incapable of not only precisely calculating the effect degree of factors on experimental indicator, but also determining the significance of each factor as a standard. Therefore, the variation analysis needs to be added to determine the significance of each factor.

The variation analysis for experimental results is to analyze the significance of each factor by comparing value of $F$ and critical value of $F$. $F$ is calculated from the sum of squares and the degree of freedom. The value of $F$ is used to show that the effect of a factor on the efficiency is less than that of experimental error if the value of $F$ is less than 1 . The variation analysis process [26] is as follows.

\section{(1) Calculation for the Sum of Squares}

(a) The Sum of Squares for Total. The sum of squares for total $\left(S_{T}\right)$ is defined as

$$
S_{T}=\sum_{k=1}^{n} x_{k}^{2}-\frac{1}{n}\left(\sum_{k=1}^{n} x_{k}\right)^{2} .
$$

$S_{T}$ resulting from variation of factor levels and experimental error shows the variation degree of the efficiency with different parameter combinations.

(b) The Sum of Squares for Factor. The sum of squares for factor is collectively named $S_{f}(f=$ A to $G)$, then the sum of squares for factor $\mathrm{A}$ is defined as

$$
\begin{aligned}
S_{\mathrm{A}}=\frac{1}{3} \sum_{i=1}^{3}\left(\sum_{j=1}^{a} x_{i j}\right)^{2}-\frac{1}{n}\left(\sum_{i=1}^{3} \sum_{j=1}^{a} x_{i j}\right)^{2} \\
(i=1,2,3, j=1 \cdots a),
\end{aligned}
$$

where $x_{i j}$ is the experimental efficiency for factor A with the $i$ th level and the $j$ th experiment. $S_{\mathrm{A}}$ shows the change of the efficiency with varying levels for factor A. Sums of squares for other factors are calculated by the same way.

(c) The Sum of Squares for Error. The sum of squares for error $\left(S_{e}\right)$ is defined as

$$
S_{e}=S_{T}-\sum S_{f}
$$

where $\sum S_{f}$ is the sum of squares for all factors. 
TABLE 8: Variance analyses in the working condition of $0.8 Q_{e}$.

\begin{tabular}{|c|c|c|c|c|c|c|}
\hline $\begin{array}{l}\text { Source of } \\
\text { variation }\end{array}$ & $\begin{array}{l}\text { Sum of } \\
\text { squares }\end{array}$ & $\begin{array}{l}\text { Degree of } \\
\text { freedom }\end{array}$ & Mean square & $F$ & Critical value & $\begin{array}{c}\text { Significance } \\
\text { (relative) }\end{array}$ \\
\hline A & 14.06 & 2 & 7.03 & 4.90 & & * \\
\hline B & 6.93 & 2 & 3.47 & 2.42 & & \\
\hline C & 12.54 & 2 & 6.27 & 4.37 & & * \\
\hline $\mathrm{D}$ & 12.25 & 2 & 6.13 & 4.27 & $\begin{array}{l}F_{0.10}(2,5)=3.78 \\
F_{0.05}(2,5)=5.79\end{array}$ & $*$ \\
\hline $\mathrm{E}$ & 118.01 & 2 & 59.00 & 41.16 & $F_{0.01}(2,5)=13.27$ & $* * *$ \\
\hline G & 41.38 & 2 & 20.69 & 14.43 & & $* * *$ \\
\hline Error & 5.24 & 5 & 1.05 & & & \\
\hline Total & 210.41 & 17 & & & & \\
\hline
\end{tabular}

Note. $* * *$ means significant effect and $*$ means slight effect.

TABLE 9: Variance analyses in the working condition of $1.0 Q_{e}$.

\begin{tabular}{|c|c|c|c|c|c|c|}
\hline $\begin{array}{l}\text { Source of } \\
\text { variation }\end{array}$ & $\begin{array}{l}\text { Sum of } \\
\text { squares }\end{array}$ & $\begin{array}{l}\text { Degree of } \\
\text { freedom }\end{array}$ & Mean square & $F$ & Critical value & $\begin{array}{c}\text { Significance } \\
\text { (relative) }\end{array}$ \\
\hline A & 22.61 & 2.00 & 11.30 & 7.12 & & $* *$ \\
\hline B & 3.76 & 2.00 & 1.88 & 1.18 & & \\
\hline $\mathrm{C}$ & 14.09 & 2.00 & 7.05 & 4.44 & & * \\
\hline $\mathrm{D}$ & 13.01 & 2.00 & 6.51 & 4.10 & $\begin{array}{l}F_{0.10}(2,5)=3.78 \\
F_{0.05}(2,5)=5.79\end{array}$ & $*$ \\
\hline $\mathrm{E}$ & 97.14 & 2.00 & 48.57 & 30.61 & $F_{0.01}(2,5)=13.27$ & $* * *$ \\
\hline G & 37.05 & 2.00 & 18.52 & 11.67 & & $* *$ \\
\hline Error & 4.10 & 5 & 0.82 & & & \\
\hline Total & 191.76 & 17 & & & & \\
\hline
\end{tabular}

Note. $* * *$ means significant effect, $* *$ means visible effect, and $*$ means slight effect.

(2) Calculation for the Degree of Freedom. The total degree of freedom is $f_{T}$ defined as $f_{T}=n-1=18-1=17$, where $n$ is the total number of experiments. The degree of freedom for factor is collectively named $f_{f}$ (subscript $f=$ A to $G$ ). Take, for example, the degree of freedom for factor $\mathrm{A}, f_{\mathrm{A}}=n_{\mathrm{A}}-1=$ $3-1=2$, where $n_{\mathrm{A}}$ is the number of levels for factor $\mathrm{A}$. The degree of freedom for experimental error is $f_{e}$ calculated by the total degree of freedom minus degrees of freedom for all factors, that is, $f_{e}=f_{T}-f_{\mathrm{A}}-f_{\mathrm{B}}-f_{\mathrm{C}}-f_{\mathrm{D}}-f_{\mathrm{E}}-f_{\mathrm{G}}=$ $17-2-2-2-2-2-2-2=5$.

(3) Calculation for the Mean Square Value. The sum of squares for factor $\left(S_{f}\right)$ affected by the number of additive data does not accurately reflect the influence of each factor. Therefore, the mean value of the sum of squares is needed to be calculated. The definitions for both the mean square value of factor $\left(M S_{f}\right)$ and the mean square value of error $\left(M S_{e}\right)$ are given in the same way, respectively, and defined as $M S_{f}=S_{f} / f_{f}, M S_{e}=S_{e} / f_{e}$.

(4) Calculation for Value of $F$. The value of $F$ shows the effect degree of each factor on the efficiency, which is defined as

$$
F=\frac{M S_{f}}{M S_{e}} .
$$

(5) Significance Test for Factors. Variation analyses in the working condition of $0.8 Q_{e}, 1.0 Q_{e}$, and $1.2 Q_{e}$ using the above method are shown in Tables 8-10. In the working condition of $0.8 Q_{e}$, factors $\mathrm{E}$ and $\mathrm{G}$ have significant effects on the result, while factors $\mathrm{A}, \mathrm{C}$, and $\mathrm{D}$ have slight effects on the result. In the working condition of $1.0 Q_{e}$, factor $\mathrm{E}$ has significant effects on the result, and factors $A$ and $G$ also have visible effects on the result, while factors $C$ and $D$ have slight effects on the result. In the working condition of $1.2 Q_{e}$, factor $\mathrm{E}$ has significant effects on the result, and factor $G$ also has visible effects on the result, while factors A, C, and D have slight effects on the result.

The effect degree of each factor on water turbine efficiency is, in order, E, G, A, C, D, B, which has basically consistent tendency with the result of the range analysis. Therefore, the water turbine with the optimal parameter combination resulting from the range analysis is receivable.

4.4. Flow Field Analysis. The internal flow analysis was conducted to reveal the principle of performance improvement by comparing the optimized and original water turbines. The runner of the optimized water turbine was modeled as shown in Figure 6.

The velocity distribution in mid-axial section of water turbine is shown in Figure 7. Both the velocities around blade outlet and draft tube wall of the optimized water turbine are lower than those of the original. The optimized water turbine just presents slight higher velocity in draft tube inlet. It indicates that the optimized water turbine has the ability to transform more kinetic energy to pressure energy. 
TABLE 10: Variance analyses in the working condition of 1.2Qe.

\begin{tabular}{|c|c|c|c|c|c|c|}
\hline $\begin{array}{l}\text { Source of } \\
\text { variation }\end{array}$ & $\begin{array}{l}\text { Sum of } \\
\text { squares }\end{array}$ & $\begin{array}{c}\text { Degree of } \\
\text { freedom }\end{array}$ & Mean square & $F$ & Critical value & $\begin{array}{c}\text { Significance } \\
\text { (relative) }\end{array}$ \\
\hline A & 33.19 & 2.00 & 16.59 & 11.08 & & * \\
\hline B & 3.50 & 2.00 & 1.75 & 1.17 & & \\
\hline C & 15.11 & 2.00 & 7.55 & 5.05 & & * \\
\hline $\mathrm{D}$ & 11.61 & 2.00 & 5.80 & 3.88 & $\begin{array}{l}F_{0.10}(2,5)=3.78 \\
F_{0.05}(2,5)=5.79\end{array}$ & $*$ \\
\hline $\mathrm{E}$ & 90.32 & 2.00 & 45.16 & 30.17 & $F_{0.01}(2,5)=13.27$ & $* * *$ \\
\hline G & 32.78 & 2.00 & 16.39 & 10.95 & & $* *$ \\
\hline Error & 3.98 & 5 & 0.80 & & & \\
\hline Total & 190.48 & 17 & & & & \\
\hline
\end{tabular}

Note. $* * *$ means significant effect, $* *$ means visible effect, and $*$ means slight effect.

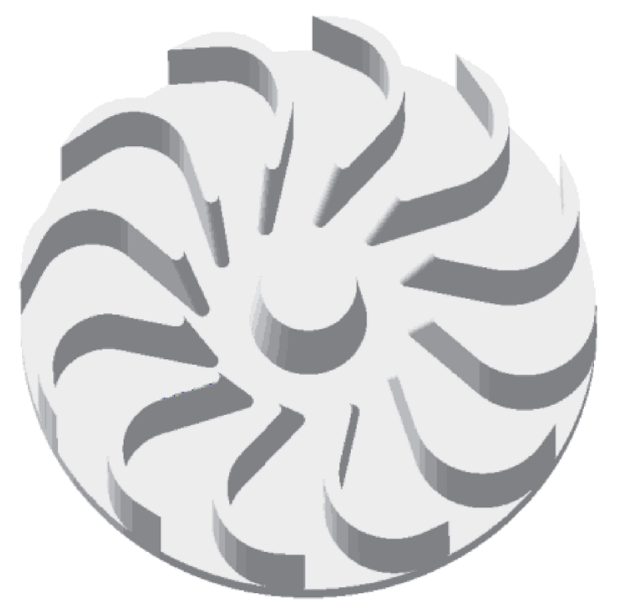

FIGURE 6: Runner of optimized water turbine.

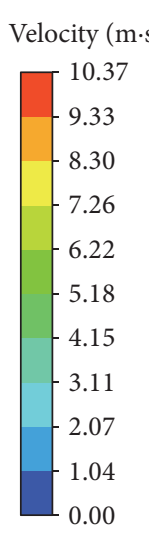

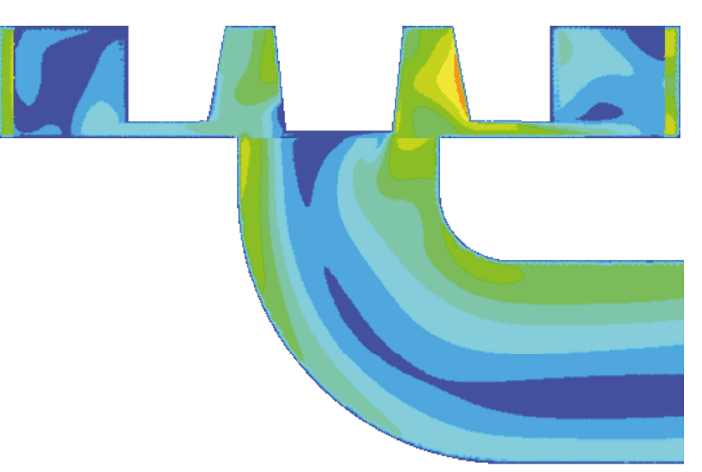

(a) Original

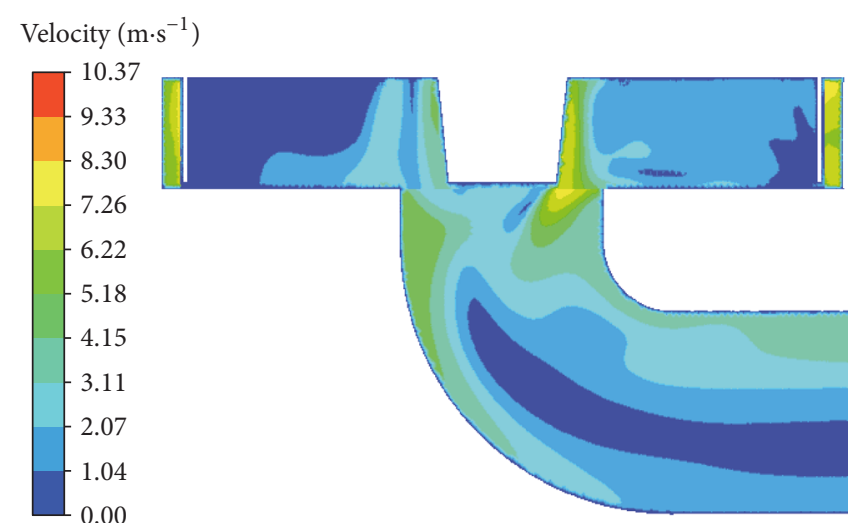

(b) Optimized

FIGURE 7: Velocity distribution in mid-axial section of water turbine.

The pressure distribution in radial mid-span section of water turbine is shown in Figure 8. The pressure distribution in radial mid-span section of the optimized water turbine is more evenly than that of the original. The high pressure region around blade tip circumference of the optimized water turbine is narrower than that of the original.
The pressure distribution in mid-axial section of water turbine is presented in Figure 9. The pressure in inlet circle of the runner for the optimized water turbine is obviously lower than that for the original, while the pressure in draft tube inlet of the optimized water turbine is visibly higher than that for the original. It indicates that the pressure energy rallies 


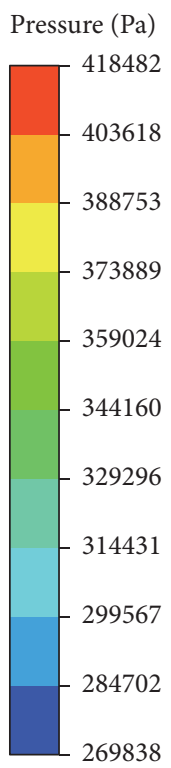

269838

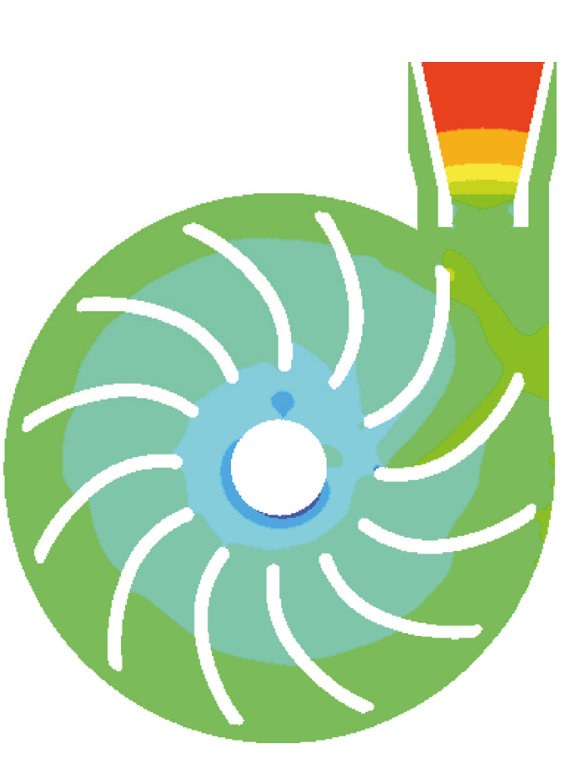

(a) Original

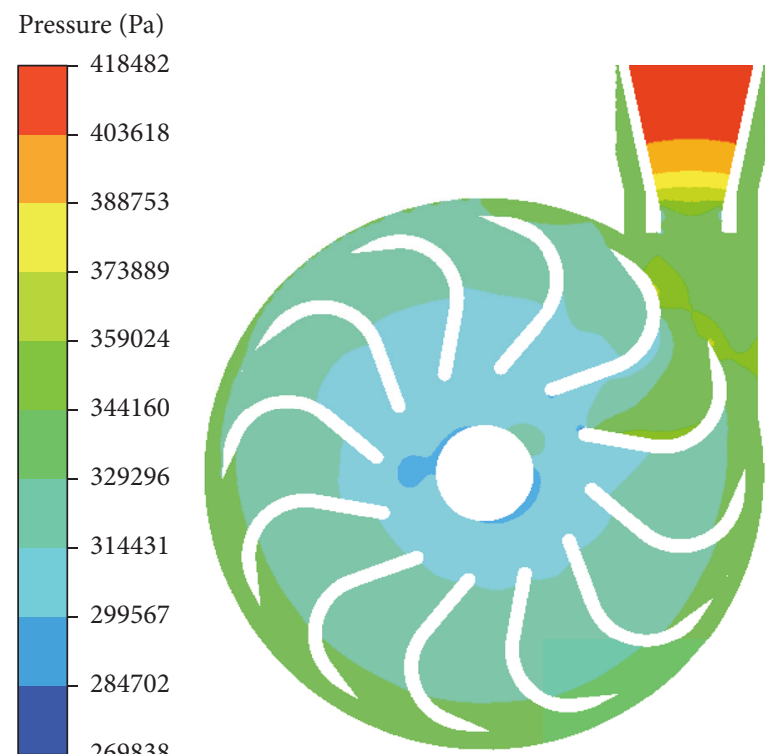

(b) Optimized

FiguRE 8: Pressure distribution in radial mid-span section of water turbine.

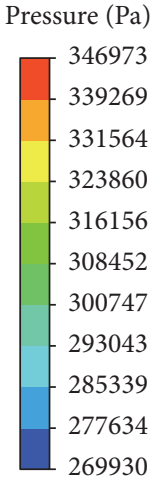

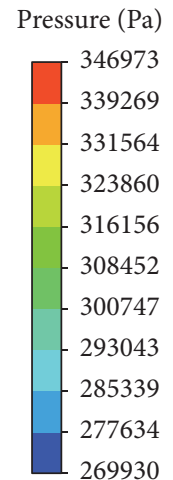

(a) Original

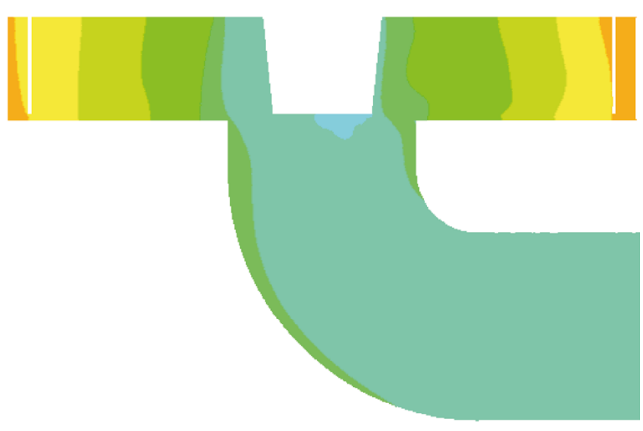

(b) Optimized

FIGURE 9: Pressure distribution in mid-axial section of water turbine.

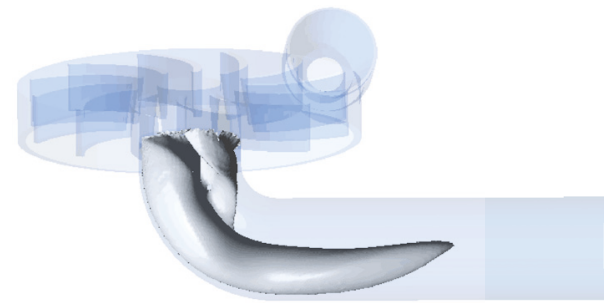

(a) Original

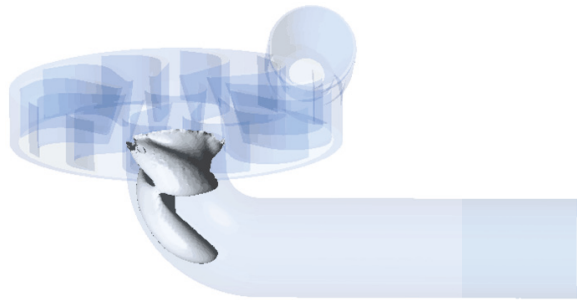

(b) Optimized

FIGURE 10: Vortex structure in draft tube.

substantially in draft tube for the optimized water turbine, and the low pressure region in the inlet of draft tube for the original tends to induce the vortex.

The method of Q-Criterion is used to detect vortices considering that the pressure distribution is unable to visually display the vortex. The $Q$ is the second invariant of the velocity gradient tensor. The vortex structure in draft tube with the level of 0.04Q is shown in Figure 10. The vortex zone for the original almost occupies the whole bend section of the draft tube and extends even longer in helical manner. The flow 


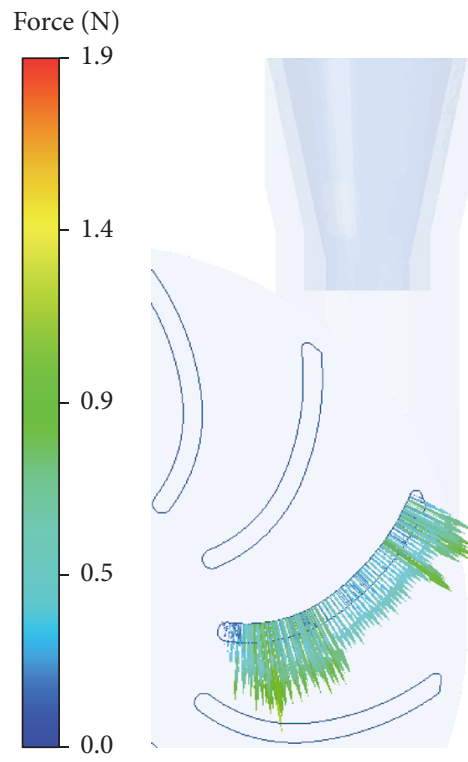

Force $(\mathrm{N})$

(a)

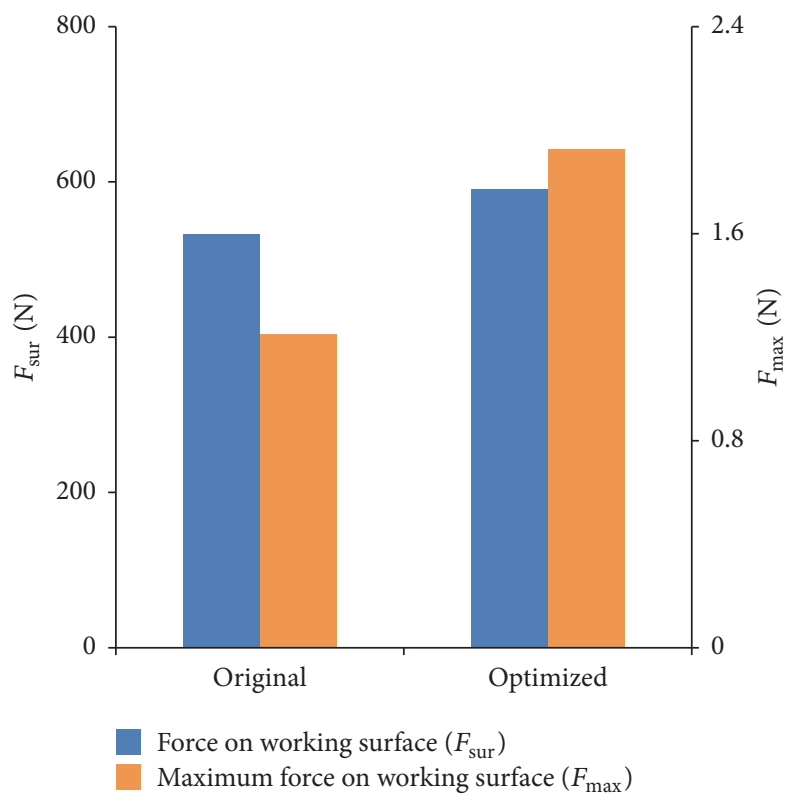

(c)

\section{卷}

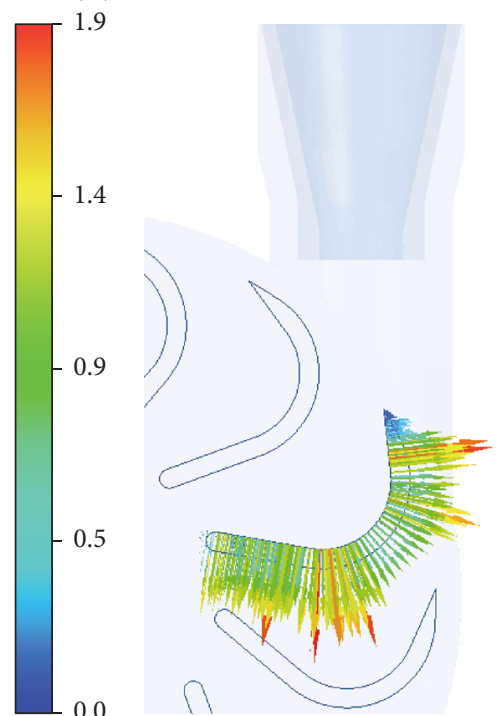

(b)

(c) Comparisons of force on working surface.

structure with the large volume of the vortex likely induces the vibration of the draft tube. However, for the optimized water turbine, the vortex just takes up half of the bend section of draft tube and has fully developed before going across the bend section. This behavior makes for improving flow characteristics in the draft tube and diminishes the vibration induced by the unsteady flows.

The load distribution on the working surface of runner is presented in Figure 11. Larger forces on the working surface for both the optimized water turbine and the original concentrate on the blade tip and blade lower-middle part, but the force magnitude of the optimized turbine is obviously larger than that of the original. In the rated flow, the maximum force on the working surface for the optimized turbine is 59\% higher than that for the original, and the resultant force on the working surface for the optimized turbine is $11 \%$ higher than that for the original. The larger blade load generates greater rotating torque for the runner. Thus the optimized turbine is 


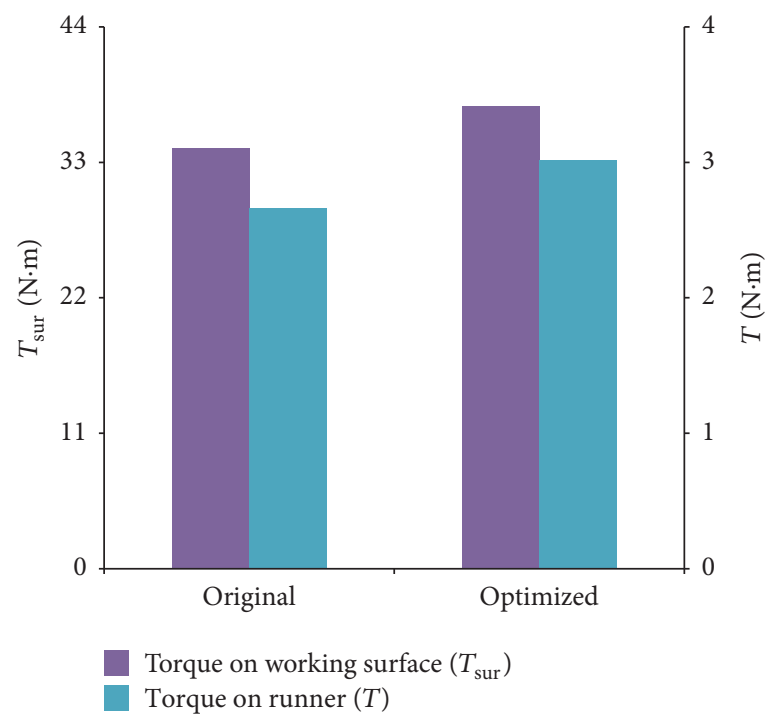

FIGURE 12: Torques on working surface and runner.

capable of delivering greater torque than the original. Torques on the working surface and the runner are shown in Figure 12. In the rated flow, the torque on the working surface of the optimized turbine is $10 \%$ higher than that of the original, and the torque on the optimized runner is $13 \%$ higher than that of original. The greater torque indicates higher output of water turbine. So the optimized water turbine delivers greater output; that is, this turbine has the better performance.

4.5. Hydraulic Performance Analysis. The performance predictions of the original and the optimized water turbine for the rotational speed ranging from $500 \mathrm{rpm}$ to $900 \mathrm{rpm}$ are shown in Figure 13. The efficiency of the optimized water turbine at the rated condition with the rotational speed of $700 \mathrm{rpm}$ and the flow rate of $17.5 \mathrm{~m}^{3} / \mathrm{h}$ is $39.6 \%$, which is 5.8 percentage points higher than that of the original (33.8\%). Thus, the optimized water turbine has the obvious performance improvement in the operating flow rate (from $15 \mathrm{~m}^{3} / \mathrm{h}$ to $\left.21 \mathrm{~m}^{3} / \mathrm{h}\right)$.

\section{Conclusion}

In this work, the micro impulse water turbine with superlow specific speed was optimized to improve the performance characteristics, based on the orthogonal array together with the numerical calculation. The experiment for the original water turbine was conducted in an open test rig. Its result has a good agreement with the numerical simulations, which was used to verify the accuracy of numerical methods.

Six main geometry parameters of the water turbine runner, including number of blades $Z$, blade tip clearance $\delta$, width of blade $b$, inlet blade angle $\beta_{p}$, blade outlet diameter $D_{2}$, and inclination angle of blade outlet $\gamma_{2}$, were selected as factors in orthogonal array. The efficiency of water turbine was chosen as the experimental indicator in the process of statistical analysis. Specifically, the range analysis presents the variation trend of the factor with different levels and the optimal combination of factors (A2, B1, C3, D1, E1, G3). The variance analysis shows that the effect degree of each factor on water turbine efficiency is, in order, $\mathrm{E}\left(D_{2}\right), \mathrm{G}\left(\gamma_{2}\right)$, $\mathrm{A}(Z), \mathrm{C}(b), \mathrm{D}\left(\beta_{p}\right), \mathrm{B}(\delta)$, and factor $\mathrm{B}$ almost has no effect on the water turbine efficiency. The variance analysis result has a basically consistent tendency with the range analysis result, so the optimal parameter combination calculated from the statistical analysis is receivable to structure a new water turbine with the better performance.

The internal flow characteristics and hydraulic performance of the optimized water turbine were investigated by comparing with the original. The pressure distribution in the optimized water turbine is more evenly than that in the original. The vortex in draft tube of the optimized water turbine generated from the lower velocity near the blade outlet and the higher pressure around the draft tube inlet is smaller than that in the original. Moreover, the blade inlet of the optimized water turbine has a larger curvature so that the jet flow from the nozzle concentrates in the impacted area of the blade. As a result, the runner torque of the optimized water turbine was $13 \%$ higher than that of the original and the water turbine efficiency was improved by 5.8 percentage points at the rated operating condition.

\section{Conflicts of Interest}

The authors declare that there are no conflicts of interest regarding the publication of this paper.

\section{Acknowledgments}

This work was supported by the National Key Research and Development Program (2016YFC0400202). 


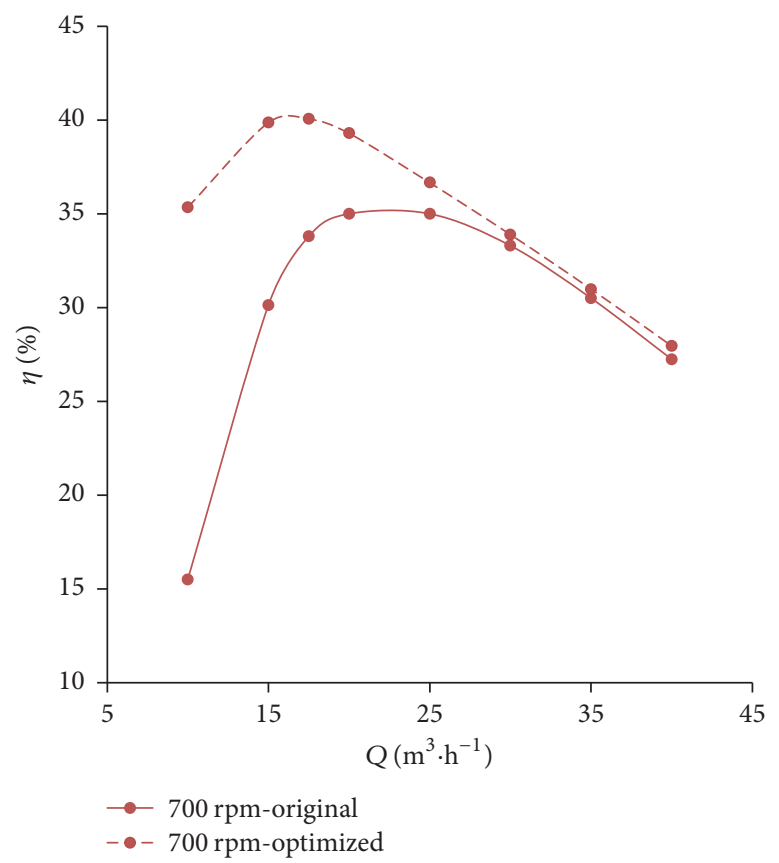

(a)

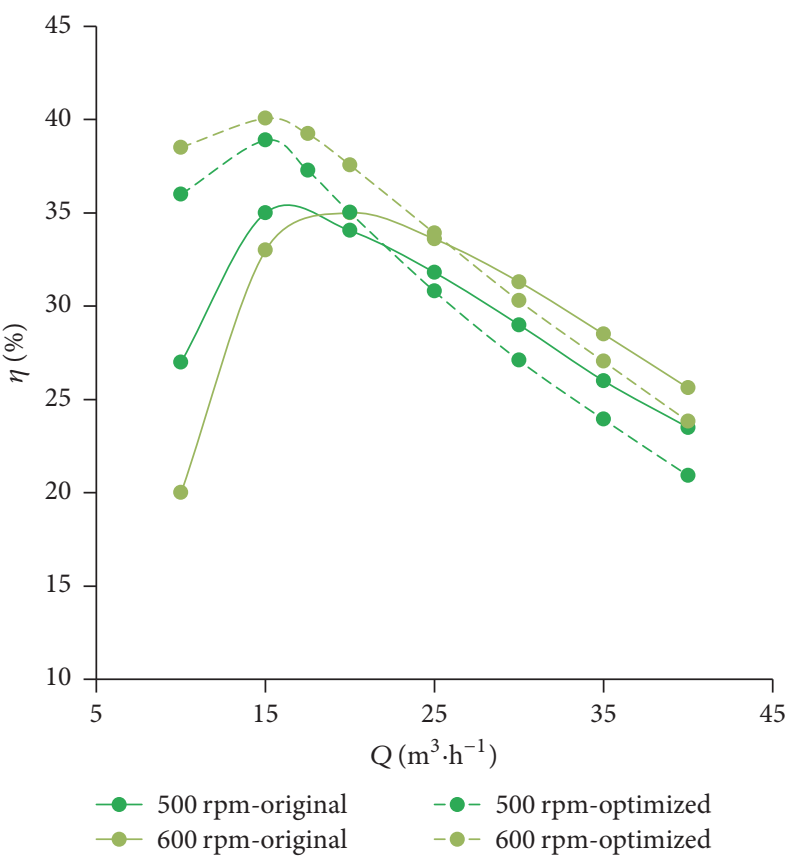

(b)

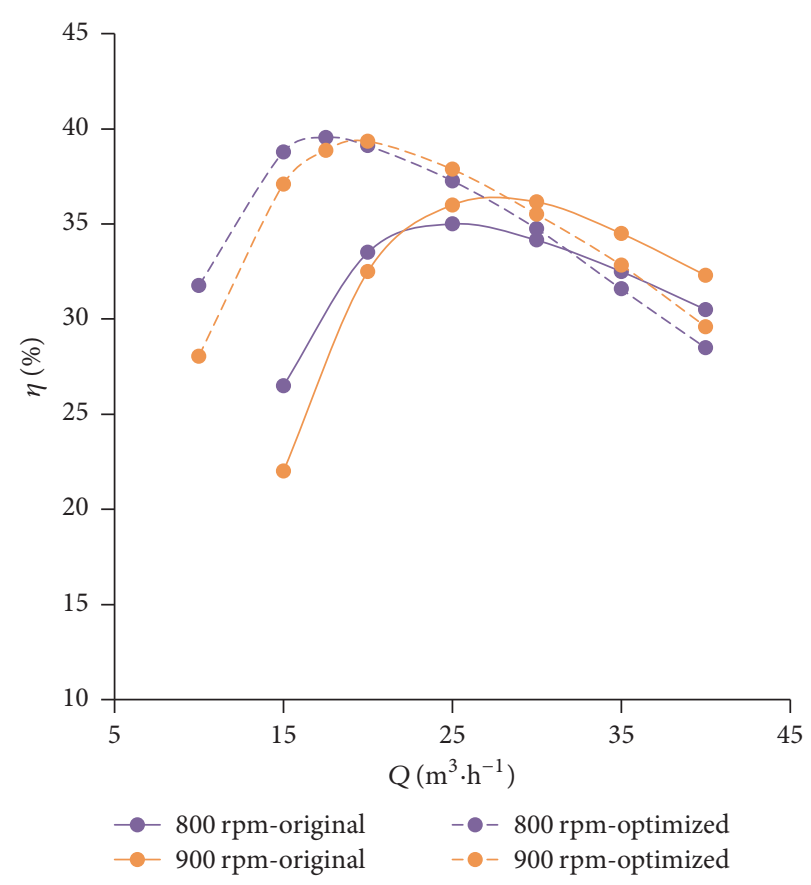

(c)

Figure 13: Performance curves of the water turbine. (a) Rated rotation speed condition. (b) Low rotation speed condition. (c) High rotation speed condition.

\section{References}

[1] P. Bansal and N. Marshall, "Feasibility of hydraulic power recovery from waste energy in bio-gas scrubbing processes," Applied Energy, vol. 87, no. 3, pp. 1048-1053, 2010.

[2] S. Mirza, "Reduction of energy consumption in process plants using nanofiltration and reverse osmosis," Desalination, vol. 224, no. 1-3, pp. 132-142, 2008.
[3] H. J. Van Antwerpen and G. P. Greyvenstein, "Use of turbines for simultaneous pressure regulation and recovery in secondary cooling water systems in deep mines," Energy Conversion and Management, vol. 46, no. 4, pp. 563-575, 2005.

[4] Y. Junhu, Z. Xuening, Wang X. et al., "Progress in energy recovery hydraulic turbine research," Chemical Machinery, vol. 38, no. 6, pp. 655-658, 2011. 
[5] L. Yanpin, N. Haipeng, and C. Dexin, "Performance and type selection of special hydraulic turbine in cooling tower," Journal of Hydroelectric Engineering, vol. 30, no. 1, pp. 175-179, 2011.

[6] L. Yanpin, K. Wang, N. Haipeng et al., "Nan Haipeng, , The approximate calculation of the flow capacity of special turbine in cooling tower," Journal of Xian University of Technology, vol. 27, no. 1, pp. 79-82, 2011.

[7] Z. Lanjin, C. Dexin, R. Yan et al., "Hydraulic loss analysis of the micro francis turbine of cooling towers," Journal of North China Institute of Water Conservancy and Hydroelectric Power, vol. 33, no. 1, p. 1, 2012.

[8] Z. Lanjin, L. Yang, C. Dexin et al., "Saved-energy analysis of francis turbine on hydraulic cooling tower," Renewable Energy Resources, vol. 30, no. 7, pp. 123-128, 2012.

[9] Z. Fei, Y. Zheng, F. Xiaojuan et al., "Design and numerical simulation of small francis turbine used in cooling tower," Water Resources and Power, vol. 31, no. 7, pp. 165-168, 2013 (Chinese).

[10] Z. Kaining, L. Li, and X. Kaige, "Hydraulic design and numerical simulation of super low specific speed francis turbine runner," Energy Engineering, vol. 4, pp. 6-9, 2012.

[11] L. Zhang, Y. Zheng, C. Zhang, Y. Yin, and J. Liu, "Study on Francis turbine with super-low specific speed applied in cooling towers," Transactions of the Chinese Society of Agricultural Machinery, vol. 41, no. 1, pp. 39-72, 2010.

[12] Y. Tang, Z. Xiangyuan, M. Xingxin et al., "performance test of water turbine of JP50 reel sprinkler," China Rural Water and Hydropower, vol. 2, pp. 26-29, 2014.

[13] Y. Shouqi, N. Guoping, T. Yue et al., "Experiment and numerical estimation of performance of hydraulic turbine of JP50 reel sprinkle," Journal of Drainage and Irrigation Machinery Engineering, vol. 32, no. 7, pp. 553-562, 2014.

[14] J. Jun, T. Yue, and L. Tang, "Energy consumption analysis of hydraulic turbine of JP75 hose reel irrigator," Journal of Drainage and Irrigation Machinery Engineering, vol. 34, no. 11, pp. 10081012, 2016.

[15] J. Chen, H. X. Yang, C. P. Liu, C. H. Lau, and M. Lo, "A novel vertical axis water turbine for power generation from water pipelines," Energy, vol. 54, pp. 184-193, 2013.

[16] S. Wang, C. F. Porres, M. Zuo et al., "Study of impeller design for pipe flow generator with CFD and RP," in Proceedings of the 10th Asian International Conference on Fluid Machinery, pp. 265-275, Kuala Lumpur, Malaysia, 2010.

[17] S. Wang and R. Doblado, "Computational and experimental study of a coaxial pipe flow generator," International Symposium on Computer, vol. 132, no. 42, pp. 435-439.

[18] L. Song, H.-Z. Liu, and Z.-X. Yang, "Orthogonal analysis based performance optimization for vertical axis wind turbine," Mathematical Problems in Engineering, vol. 2016, Article ID 6241360, 11 pages, 2016.

[19] J. H. Yang and S. C. Miao, "Numerical simulation and orthogonal design method research effect of splitter blade's main geometry factors on the performance of pump as turbine," Applied Mechanics and Materials, vol. 456, pp. 100-105, 2014.

[20] K.-K. Lee, K.-H. Lee, and S.-H. Han, "Use of an orthogonal array based on the Kriging model to maximize the fatigue life of a turbine blade," International Journal of Structural Integrity, vol. 2, no. 3, pp. 303-313, 2011.

[21] J. Tang, G. Gong, H. Su, F. Wu, and C. Herman, "Performance evaluation of a novel method of frost prevention and retardation for air source heat pumps using the orthogonal experiment design method," Applied Energy, vol. 169, pp. 696-708, 2016.
[22] Z. Li and O. P. Malik, "An orthogonal test approach based control parameter optimization and its application to a hydroturbine governor," IEEE Transactions on Energy Conversion, vol. 12, no. 4, pp. 388-393, 1997.

[23] J. S. Liu, J. L. Cheng, and Y. Gong, "Study on optimal scheduling methods of urban drainage pumping stations based on orthogonal test," Applied Mechanics and Materials, vol. 373-375, pp. 2169-2174, 2013.

[24] F. R. Menter, "Review of the shear-stress transport turbulence model experience from an industrial perspective," International Journal of Computational Fluid Dynamics, vol. 23, no. 4, pp. 305-316, 2009.

[25] P. Huang, J. Bardina, and T. Coakley, "Turbulence modeling validation," in Proceedings of the 28th Fluid Dynamics Conference, Snowmass Village, CO, USA.

[26] I. Korkut and Y. Kucuk, "Experimental analysis of the deviation from circularity of bored hole based on the taguchi method," Strojniski Vestnik: Journal of Mechanical Engineering, vol. 56, no. 5, pp. 340-346, 2010. 


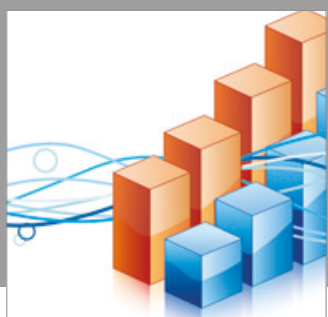

Advances in

Operations Research

vatersals

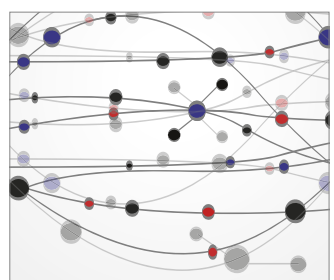

\section{The Scientific} World Journal
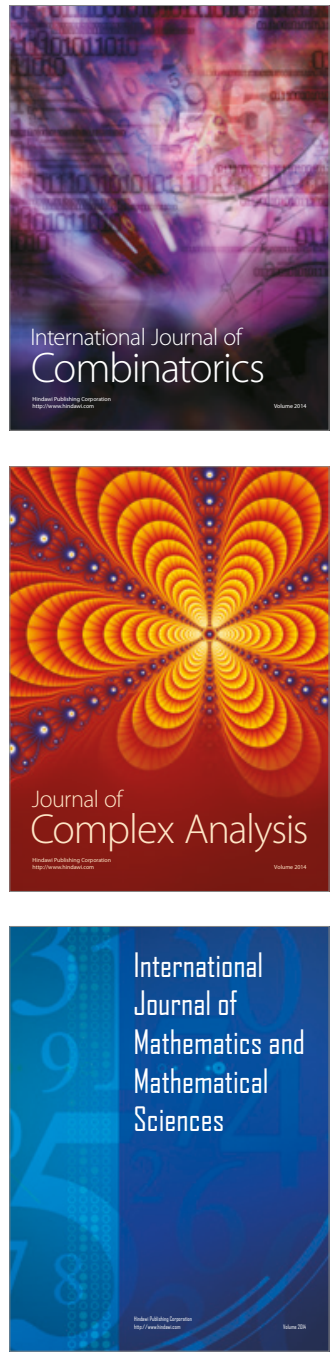
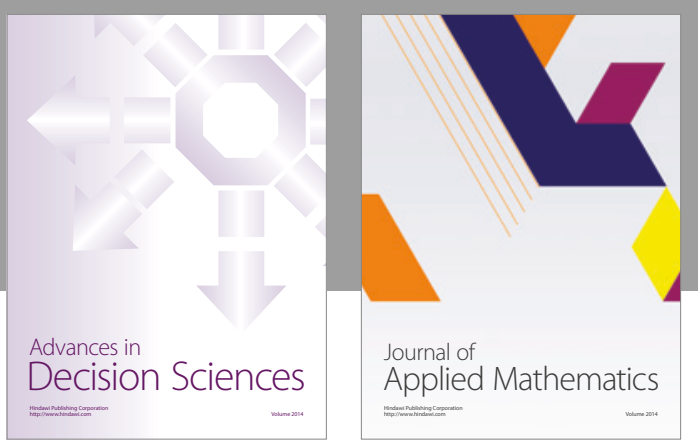

Algebra

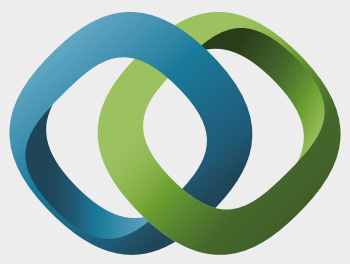

\section{Hindawi}

Submit your manuscripts at

https://www.hindawi.com
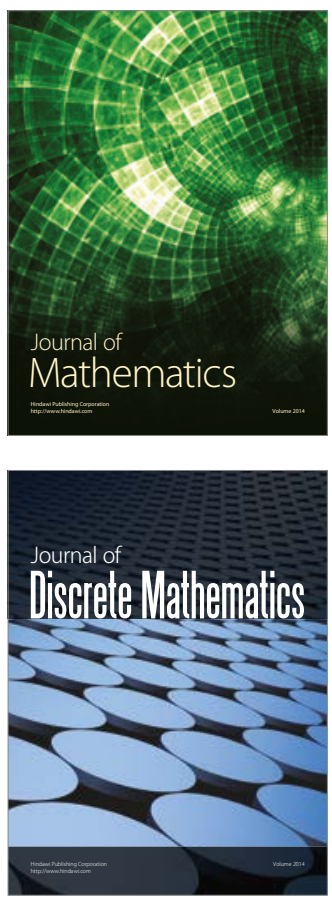

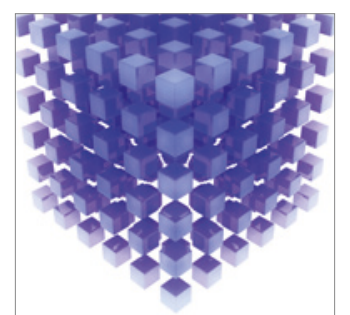

Mathematical Problems in Engineering
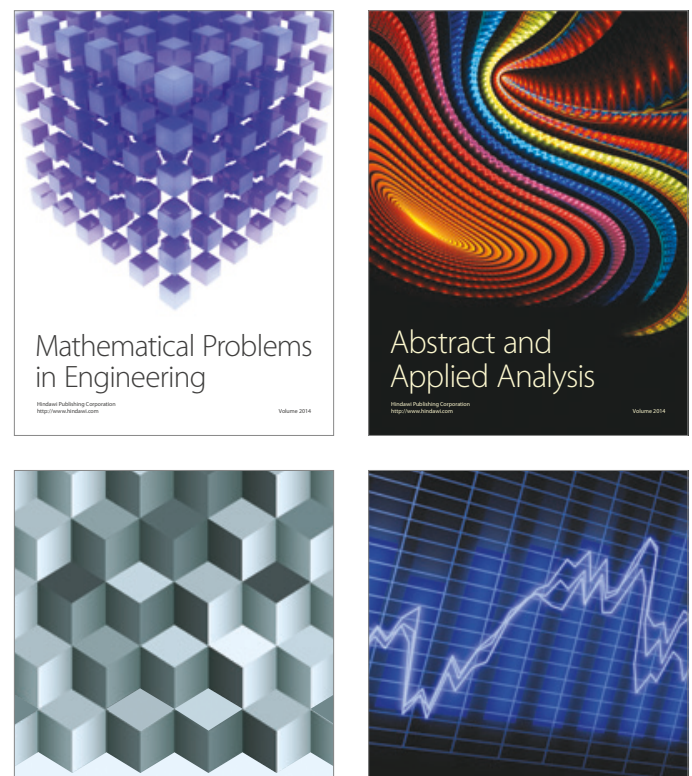

Journal of

Function Spaces

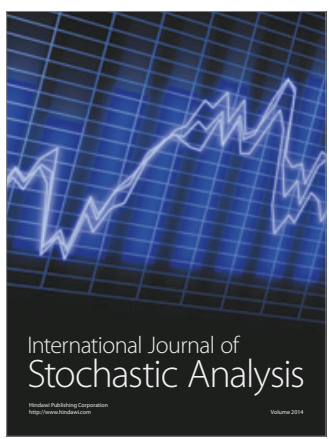

Probability and Statistics
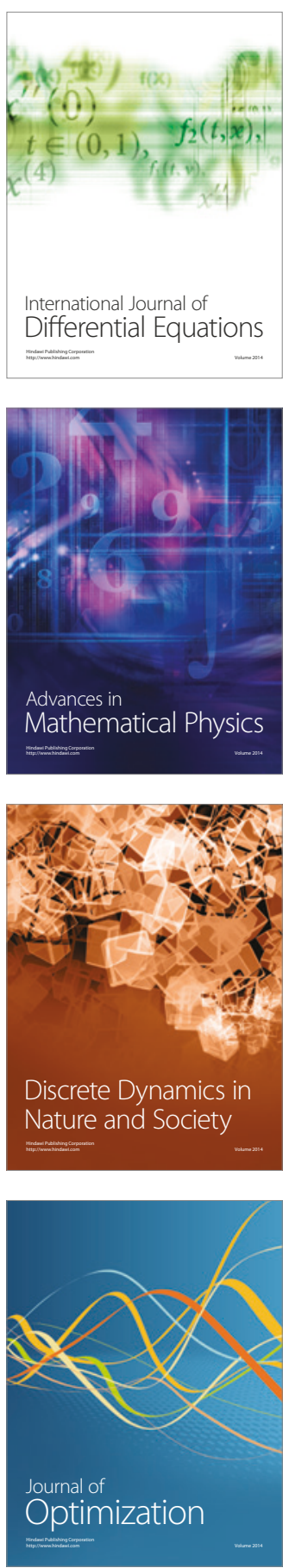